Cochrane Database of Systematic Reviews

\title{
Buflomedil for intermittent claudication (Review)
}

de Backer TLM, Vander Stichele R

de Backer TLM, Vander Stichele R.

Buflomedil for intermittent claudication.

Cochrane Database of Systematic Reviews 2013, Issue 3. Art. No.: CD000988.

DOI: 10.1002/14651858.CD000988.pub4.

www.cochranelibrary.com 
TABLE OF CONTENTS

HEADER 1

ABSTRACT

PLAIN LANGUAGE SUMMARY

BACKGROUND

OBJECTIVES

METHODS

RESULTS

DISCUSSION

AUTHORS' CONCLUSIONS

ACKNOWLEDGEMENTS

REFERENCES

CHARACTERISTICS OF STUDIES

DATA AND ANALYSES

Analysis 1.1. Comparison 1 Buflomedil versus placebo, Outcome 1 Painfree walking distance. Meters gain.

Analysis 1.2. Comparison 1 Buflomedil versus placebo, Outcome 2 Maximal walking distance. Meters gain. ADDITIONAL TABLES

APPENDICES

WHAT'S NEW

HISTORY

CONTRIBUTIONS OF AUTHORS

DECLARATIONS OF INTEREST

SOURCES OF SUPPORT

INDEX TERMS

1

2

3

3

3

4

5

7 
[Intervention Review]

\section{Buflomedil for intermittent claudication}

Tine LM de Backer1,2, Robert Vander Stichele 2

${ }_{1}^{1}$ Heart Center, Ghent University Hospital, Ghent, Belgium. 2Heymans Institute of Pharmacology, Ghent University, Ghent, Belgium

Contact address: Tine LM de Backer, Heart Center, Ghent University Hospital, De Pintelaan 185, Ghent, B-9000, Belgium.

tine.debacker@ugent.be,t_de_backer@hotmail.com.

Editorial group: Cochrane Vascular Group

Publication status and date: New search for studies and content updated (no change to conclusions), published in Issue 3, 2013.

Citation: de Backer TLM, Vander Stichele R. Buflomedil for intermittent claudication. Cochrane Database of Systematic Reviews 2013, Issue 3. Art. No.: CD000988. DOI: 10.1002/14651858.CD000988.pub4.

Copyright @ 2013 The Cochrane Collaboration. Published by John Wiley \& Sons, Ltd.

\section{A B S T R A C T}

\section{Background}

Intermittent claudication (IC) is pain caused by chronic occlusive arterial disease, that develops in a limb during exercise and is relieved with rest. Buflomedil is a vasoactive agent used to treat peripheral vascular disease. However, its clinical efficacy for IC has not yet been critically examined. This is an update of a Cochrane review first published in 2000, and previously updated in 2007 and 2008.

\section{Objectives}

To evaluate the available evidence on the efficacy of buflomedil for IC.

\section{Search methods}

For this update the Cochrane Peripheral Vascular Diseases Group Trials Search Co-ordinator searched the Specialised Register (last searched January 2013) and CENTRAL (2012, Issue 12).

\section{Selection criteria}

Double-blinded, randomized controlled trials (RCTs) in patients with IC (Fontaine stage II) receiving oral buflomedil compared with placebo. Pain-free walking distance (PFWD) and maximum walking distance (MWD) were analysed by standardized exercise test.

\section{Data collection and analysis}

Two authors independently assessed trial quality and extracted data. We contacted study authors for additional information.

\section{Main results}

We included two RCTs with 127 participants. Both RCTs showed moderate improvements in PFWD for patients on buflomedil. This improvement was statistically significant for both trials (WMD $75.1 \mathrm{~m}, 95 \%$ confidence interval $(\mathrm{Cl}) 20.6$ to 129.6 ; WMD $80.6 \mathrm{~m}, 95 \% \mathrm{Cl} 3.0$ to 158.2), the latter being a wholly diabetic population. For both RCTs, MWD gains were statistically significant with wide confidence intervals (WMD $80.7 \mathrm{~m}, 95 \% \mathrm{Cl} 9.4$ to 152 ; WMD $171.4 \mathrm{~m}, 95 \% \mathrm{Cl} 51.3$ to 291.5 ), respectively.

\section{Authors' conclusions}

There is little evidence available to evaluate the efficacy of buflomedil for IC. Most trials were excluded due to poor quality. The two included trials showed moderately positive results; these are undermined by publication bias since we know of at least another four unpublished, irretrievable, and inconclusive studies.

Buflomedil's benefit is small in relation to safety issues and its narrow therapeutic range. 


\section{PLAIN LANGUAGE SUMMARY}

\section{Buflomedil for intermittent claudication}

Intermittent claudication (IC) is pain that develops in a limb (mostly calves and thighs) during exercise and is relieved with rest. It is caused by insufficient blood flow due to peripheral arterial occlusive disease.

Treatment should contain all measures of secondary prevention of cardiovascular diseases. Regular exercise and smoking cessation is the most effective therapy to improve the symptoms of claudication. Drug treatments include vasoactive agents to improve blood flow (such as vasodilators and other hemorheologic agents that reduce blood viscosity), anticoagulants, antiplatelet agents and lipid-lowering agents. Only a minority of patients undergo angioplasty or vascular surgery.

Buflomedil is a vasoactive agent widely used to treat intermittent claudication. The review authors identified eleven trials but could not use nine of them because of the methodologies used and high risk of bias. The two remaining controlled trials randomised a total of 127 participants to receive buflomedil or placebo for at least three months. One of these trials involved 40 participants with diabetes. Taken together, the trials showed moderately positive results for improvements in pain-free walking distance on a treadmill $(76.9 \mathrm{~m}, 95 \% \mathrm{Cl} 32.3$ to 121.5$)$ and maximum walking distance ( $112.6 \mathrm{~m}, 95 \% 27.7$ to 197.5$)$ with buflomedil for 12 weeks, showing a wide variation in benefit between participants.

The excluded studies consisted of three small marginally positive studies and one larger negative study. At least another four unpublished studies could not be retrieved and were reported to have inconclusive results.

Recent safety concerns have been raised about buflomedil because of lethal and non-lethal neurologic and cardiovascular advents events in cases of accidental and voluntary overdoses.

The benefit of buflomedil is small in light of relatively little evidence on efficacy and narrow therapeutic range along with recent safety issues. 


\section{B A C K G R O U N D}

\section{Description of the condition}

Chronic occlusive arterial disease of the lower extremities can present itself in different ways:

1. asymptomatic arterial insufficiency;

2. symptomatic disease presenting as intermittent claudication, i.e. pain that develops in the affected limb with exercise and is relieved with rest;

3. rest pain with, or without, atrophic skin disorders;

4. critical leg ischemia, in which the ischemic process endangers part or all of the lower extremity.

Atherosclerosis is the most common cause of chronic arterial occlusive disease of the lower extremities. It causes arterial narrowing, or occlusion, which reduces blood flow to the lower limb during exercise or at rest. In the clinical condition of intermittent claudication, the severity of the symptoms depends upon the extent of the narrowing and the collateral circulation.

\section{Description of the intervention}

Patients with intermittent claudication are most often managed conservatively. Only a minority (10\% to $25 \%$ ) (Verhaeghe 1998) of the patients undergo angioplasty or vascular surgery. Regular exercise (Leng 2000) and smoking cessation can improve the symptoms of claudication and may be beneficial for the often associated coronary artery or cerebrovascular disease or both.

Conservative treatment should achieve:

1. improvement of functional capacity, i.e. an increase in walking distance;

2. inhibition of progression of atherosclerotic lesions;

3. reduction of cardiac and cerebrovascular morbidity and mortality.

Many types of drugs are used in the treatment of intermittent claudication: vasoactive agents (vasodilators and hemorheologic agents), antithrombotic agents, antiplatelet agents, lipid-lowering agents. Trials have also been performed with vitamin E (Kleijnen 1998), garlic (Jepson 1997) and sex hormones (Price 2001) with varying results.

\section{How the intervention might work}

Vasodilators cause vasodilation in the arterioles of the lower limbs. However, they are thought to be ineffective because large vessel dimensions are fixed by the atherosclerotic process and collaterals are already maximally dilated in patients with intermittent claudication. Sometimes vasodilators may even worsen ischemia due to a 'steal' phenomenon. Hence, the interest has shifted from vasodilators to drugs that improve flow by altering viscosity. Decreased erythrocyte deformability and abnormal whole blood viscosity are present in patients with peripheral arterial disease and offer potential therapeutic targets for agents that affect viscosity (hemorheologic agents). One of these agents is buflomedil, for which beneficial effects on microcirculation of the legs and on cerebral blood flow in patients with cerebrovascular disease have been claimed. Pathophysiological research has shown that buflomedil inhibits platelet aggregation, may improve red cell deformability and reduces whole blood and plasma viscosity by reducing plasma fibrinogen (Bevan 1992).

\section{Why it is important to do this review}

Buflomedil was registered before the era of rigorous regulatory review and was accepted for peripheral arterial occlusive disease (PAOD) and for cerebrovascular disease. Its exact market for these two indications is not known but is predominantly for PAOD. The product is still widely used. Health insurers in many countries have become increasingly critical of the efficacy of this product and sometimes have restricted or abolished reimbursement. Therefore, a reassessment of the efficacy of this product is timely.

\section{OBJECTIVES}

To collect and to evaluate systematically the available evidence from placebo-controlled, double-blind randomized controlled trials (RCTs) on the efficacy of buflomedil, given orally, in intermittent claudication (Fontaine stage II) (Fontaine 1954), by measuring the pain-free walking distance (PFWD) and the maximum walking distance (MWD), with a standardized treadmill test.

\section{METHODS}

\section{Criteria for considering studies for this review}

\section{Types of studies}

Included studies were prospective, randomized, double blind, placebo-controlled, parallel or cross-over trials involving more than 30 participants. For cross-over studies, only the first period of the cross over was considered (Cameron 1988).

\section{Types of participants}

Patients with intermittent claudication in Fontaine-stage II (with the criteria explicitly described), regardless of duration of onset or smoking status. Studies including patients with inflammatory arteriopathy, thromboangiitis obliterans, acute ischemia, purely neuropathic ulceration or gangrene necessitating immediate amputation and attempted reconstruction or sympathectomy within the preceding three months or both were excluded.

\section{Types of interventions}

Interventions using buflomedil orally in doses of $300 \mathrm{mg}$ to $900 \mathrm{mg}$ per day, compared with a placebo control group.

\section{Types of outcome measures}

\section{Primary outcomes}

The primary outcome measure was the pain-free walking distance (PFWD), assessed by treadmill exercise using prespecified criteria, with a minimum of three months duration between baseline and outcome assessment.

\section{Secondary outcomes}

The secondary outcome measure was the maximum walking distance (MWD). 


\section{Search methods for identification of studies}

\section{Electronic searches}

For this update the Cochrane Peripheral Vascular Diseases Group Trials Search Co-ordinator (TSC) searched the Specialised Register (last searched January 2013) and the Cochrane Central Register of Controlled Trials (CENTRAL) 2012, Issue 12, part of The Cochrane Library (www.thecochranelibrary.com). See (Appendix 1) for details of the search strategy used to search CENTRAL. The Specialised Register is maintained by the TSC and is constructed from weekly electronic searches of MEDLINE, EMBASE, CINAHL, AMED, and through handsearching relevant journals. The full list of the databases, journals and conference proceedings which have been searched, as well as the search strategies used are described in the (Specialised Register) section of the Cochrane Peripheral Vascular Diseases Group module in The Cochrane Library (www.thecochranelibrary.com).

\section{Searching other resources}

\section{Authors' searches}

For the original review the authors searched MEDLINE for the free text string 'buflomedil'. To identify randomized controlled trials (RCTs) we first used the systematic search strategy suggested by the Cochrane Collaboration (Dickersin 1994). However, this search was too restrictive. We then simplified our search strategy by crossing the active ingredient name with the MeSH term "intermittent claudication". This resulted in references to case reports, editorials, reviews, and original study reports. We obtained the full text of the publications pertaining to intermittent claudication and checked their reference lists for additional studies. We consulted the International Pharmaceutical Abstracts. We asked Abbott, the distributor of the drug, to provide reports of controlled clinical trials available to them. From this pool of studies we extracted the placebo-controlled RCTs matching our criteria for patient selection, intervention and outcome (PIO-criteria). We finally submitted a core of relevant articles to a Science Citation Index search.

\section{Data collection and analysis}

\section{Selection of trials}

Initially, we attempted to construct a data file of individual patients with a predefined list of variables. However this failed because we were unable to retrieve individual data, either by extraction from the published report or by seeking direct access to the original data from the authors. Hence, data extraction was performed on aggregated data for walking distances, as published in the study reports.

\section{Assessment of methodological quality}

The set of retrieved trials, complying with our inclusion criteria, was then subjected to a quality assessment.

Structured abstracts were made of every original article retrieved, in order to facilitate the collective quality evaluation process among the three authors. Three authors (TDB, RVS, MGB) independently assessed articles, structured abstracts and checklists. Discrepancies were discussed until consensus was reached. In a first round of quality assessment, we used the minimal quality criteria for PAOD trials described by Cameron et al (Cameron 1988): i.e. minimum of three months duration between baseline and outcome assessment, not less than thirty participants in total, and sufficient detail in reporting of variability of results (standard deviation or standard error of the mean given). The studies were also submitted to a more fundamental assessment of internal validity, according to the model of Schulz (Schulz 1995) and the model of Jadad (Jadad 1996). According to the methodology proposed by The Cochrane Collaboration (Mulrow 1999), studies were graded " $\mathrm{A}$ " if there was a low risk of bias (no flaws in design and internal validity), "B" if there was a moderate risk of bias and " $\mathrm{C}$ " if there was a high risk of bias (major flaws in design or internal validity or both or not conforming to the minimal criteria of Cameron) (Cameron 1988).

In some publications, results were not reported in sufficient detail. Attempts were made to contact the author(s) by phone, fax or email without success in all cases.

\section{Extraction of data}

We collected data on trial duration, participants' age, sex, smoking status, presence of diabetes comorbidity, dosage, the exclusion criteria, and the location of the arterial stenosis. Finally, the dropout rates in placebo and active limb were compared.

\section{Statistical analysis}

The evidence was summarized by extracting the mean and standard deviation of the initial and final walking distances for the active substance and for placebo. The differences in incremental gain between active and placebo groups for PFWD and MWD with their confidence intervals were calculated, using an approximate method, described by Gardner and Altman (Gardner 1989a; Gardner 1989b; Gardner 1989c; Gardner 1989d).

\section{RES U L T S}

\section{Description of studies}

Eleven trials were identified as described above, but nine were subsequently excluded.

\section{Results of the search}

Our search in the bibliographic databases resulted in the identification of four eligible trials (Bisler 1983; Fonseca 1988; Limbs 2008; Trübestein 1984). We also identified a meta-analysis (Walker 1995), with references to ten trials, (Baitsch 1983; Bisler 1983; Trübestein 1984; Diamantopoulos 2001; Zinnagl 1986; Levien 1983; Lowe 1987; Lund 1988; Olsson 1986; Raithel 1985). We were able to retrieve the full text of seven eligible RCTs, six published (Bisler 1983; Diamantopoulos 2001; Fonseca 1988; Limbs 2008; Trübestein 1984; Zinnagl 1986) and one unpublished (Lowe 1987).The original text of one published trial was sent to us by the primary author (Diamantopoulos 1989). This trial was published again in 2001 (Diamantopoulos 2001). One other published (Zinnagl 1986) trial was sent to us in full text by one of the authors of the above mentioned meta-analysis. We made multiple requests for the unpublished trials (Levien 1983; Lund 1988; Olsson 1986; Raithel 1985).

\section{Included studies}

Trübestein (published trial) (Trübestein 1984), conducted a well designed multicenter trial with 113 patients. Twenty dropouts were adequately described. The duration of the intervention period was 
12 weeks. There was a statistically significant increase in PFWD and in MWD in the buflomedil group versus the placebo group.

Diamantopoulos (published trial) (Diamantopoulos 2001), conducted a rather small study $(N=40)$, with a wholly diabetic population of claudicants. There were six well described dropouts. The treatment period was six months.

\section{Excluded studies}

From the abstracts, we were able to determine that one trial (Baitsch 1983), was not eligible because the intervention was with intravenous treatment. Four trials were excluded because of high risk of bias due to problems of methodological quality: the duration of one trial was not long enough (Bisler 1983); the other three trials presented problems of internal validity and failed to give elementary details on variability of the results (Fonseca 1988; Lowe 1987; Zinnagl 1986). Four of the excluded studies consisted of three small marginally positive studies (Bisler 1983; Fonseca 1988; Zinnagl 1986) and one larger negative study (Lowe 1987).

We were unable to retrieve the full texts of the other four unpublished trials (Levien 1983; Lund 1988; Olsson 1986; Raithel 1985). In the Excluded studies table we summarized the available information from these unpublished trials extracted from the tables in the meta-analysis (Walker 1995).

The multicenter LIMB trial (Limbs 2008) randomized 2,078 Fontaine stage II PAOD patients with an $\mathrm{ABI}$ between 0.3 and 0.8 to buflomedil $300 \mathrm{mg}$ BID (150 mg twice daily in case of Creatinine (Cr) Clearance $<40 \mathrm{ml} / \mathrm{min}$ ) or placebo. Baseline characteristics in both groups were similar. After a median follow up of 2.75 years, patients on buflomedil (1,043 patients) had fewer lower limb amputations, cardiovascular death and total death compared to patients on placebo (1,035 patients) (9\% versus $12 \%)$. Patients on buflomedil had significant improvement in pain-free walking distance compared to controls (median increase of PFWD of $43 \%$ versus $0 \%$ ). The drug was well tolerated. Dr Jeffrey W Olin of Mount Sinai School of Medicine, New York, NY, criticized the findings in the trial by pointing out potential confounds and sources of error: low to zero placebo effect; $62 \%$ of patients were Russian, with the rest distributed among the Czech Republic, France and Hungary; no information to assess internal validity; measurement of $A B$ questioned; WD clinically estimated (no treadmill) (Wood 2005). The study raises many questions on the performance, results and reporting of the study. Since the author did not respond, many questions still remain unanswered.

\section{Risk of bias in included studies}

The two included trials (Diamantopoulos 2001; Trübestein 1984) were both rated "B" (moderate risk of bias) because neither would stand up to modern standards of performing and reporting clinical trials.

\section{Effects of interventions}

Trübestein 1984: Patients assessed their walking ability as improved and the sensation after physical stress as diminished. The authors only report a statistically significant increase in PFWD $(\mathrm{P}<$ $0.001)$ and MWD $(P<0.01)$ in the buflomedil group versus placebo group was found between the first (pre-trial) and fifth (after 84 days of treatment) examinations. The arithmetic means of the pressure difference (brachial artery-posterior tibial artery) in the placebo and in the buflomedil group both showed a decrease when the first and fifth visits were compared.

Diamantopoulos 2001: The patients showed significant differences at the $5 \%$ level in mean increases in walking distances between the two groups at the three month examination. Mean increases over baseline in PFWD for the buflomedil and placebo groups were $52.8 \mathrm{~m}$ and $8.6 \mathrm{~m}$ respectively $(P=0.018)$ and for MWD $81.1 \mathrm{~m}$ and $8.8 \mathrm{~m}$ respectively $(\mathrm{P}=0.022)$. The mean increases in both groups in PFWD at six months over baseline were not significantly different $(P=0.059)$ even though the actual difference was substantial (112.20 m for buflomedil; $31.6 \mathrm{~m}$ for placebo). The mean increases in MWD at six months showed a statistically significant difference ( $P=0.011)$ (191.9 $\mathrm{m}$ for buflomedil; $20.5 \mathrm{~m}$ for placebo). The systolic blood pressure indices at rest and after exercise showed no statistically significant differences between the groups. No statistically or clinically significant changes were noted in any hematological or biochemical values. The drug was well tolerated by all patients and only minor side effects were observed during the six months of treatment. All participants in this trial were diabetic.

The two RCTs accepted after quality evaluation (Trübestein 1984; Diamantopoulos 2001) showed moderately positive results for the PFWD: (WMD $75.1 \mathrm{~m}, 95 \% \mathrm{Cl} 20.6$ to 129.6 ; WMD $80.6 \mathrm{~m}, 95 \% \mathrm{Cl} 3.0$ to 158.2) metres gain of active (buflomedil) over placebo, respectively. The gains in maximum walking distance (MWD) were (WMD $80.7 \mathrm{~m}$, $95 \% \mathrm{Cl} 9.4$ to 152 ; WMD $171.4 \mathrm{~m}, 95 \% \mathrm{CI} 51.3$ to 291.5 ), respectively. Both results were statistically significant but had wide confidence intervals. Pooling of data could not be performed because only two studies conducted in heterogeneous populations were included.

\section{DISCUSSION}

Only randomized placebo-controlled trials were considered for this systematic review because the course of intermittent claudication is highly variable and there is no gold standard for pharmacological treatment of this condition. We chose the standardized treadmill test as the common outcome measure because it is the best available method to measure relevant endpoints (pain-free and/or maximum walking distances/times). Also, it is the most universal measure in studies in this research field although its value has been criticized (Wurzinger 1987). Studies on endpoints such as blood flow, blood viscosity, ankle/arm index, platelet aggregation, etc. are of interest, but the clinical relevance of changes of such endpoints by medication is not known and no correlation can be found between the clinical parameters and these surrogate endpoints (Wurzinger 1987). To the best of our knowledge, studies having mortality or amputation rate as endpoints do not exist. In any case, these would require a huge sample size because of the low frequency of these events in PAOD. Quality of life would be an interesting outcome measure. A disease-specific questionnaire, the CLAU-S scale, has been developed (Spengel 1997), and applied as an endpoint in the evaluation of naftidrofuryl versus placebo (Liard 1997). However, after careful scrutiny of the validity of the CLAU-S scale, we did not consider it to be a convincing instrument for the measurement of quality of life because it has not yet been validated against the standardized treadmill test. The CLAU-S scale has not been used in studies with buflomedil.

Our quality evaluation of the trials was pragmatic because most of the retrieved trials dated from before 1992 and did not conform 
to the modern quality criteria of conducting and reporting RCTs (Jadad 1996; Schulz 1995).

Only two more-or-less acceptable studies were included. There was large heterogeneity between patient groups in the included and excluded studies. The lack of information on the patients included, the small sample sizes and the small number of trials did not allow relevant subgroup analysis.

Pooling of the data could not be performed in that only two studies with heterogeneous populations were included.

In Walker and MacHannaford's meta-analysis (Walker 1995), nine heterogeneous studies were pooled, of which two studies (the same two as included in our analysis) showed a statistically significant difference. The remaining seven studies in their meta-analysis were not statistically significant; two were published trials excluded by us because of problems of internal validity; one trial was unpublished but retrieved by us from the author and subsequently excluded again because of problems of internal validity; four trials were unpublished, with only scant information about the quality of execution of the trial and on the variability of the results. The pooled effect size weighted for sample size of these nine studies was $0.27(\mathrm{Cl} 0.11$ to 0.42$)$ for pain-free walking distance and 0.28 ( 0.12 to 0.45$)$ for maximum walking distance, which cannot be considered as a convincing indication of efficacy.

It is unlikely that we have missed studies with a positive result in our quest for evidence. We know of the existence of four unpublished buflomedil trials (Levien 1983; Lund 1988; Olsson 1986; Raithel 1985) which were cited in a meta-analysis (Walker 1995). After examination of the effect sizes of these unpublished trials as reported in this meta-analysis, their results can be considered to be inconclusive. This contrasts with the approach and optimistic conclusions of the meta-analysis of Walker and Mac Hannaford (Walker 1995).

Hence, we concluded that under these circumstances statistical pooling is not appropriate and that the evidence on the efficacy of buflomedil is insufficient, and affected by publication bias.

Also recently the safety of buflomedil came into attention. In 2006, a safety crisis emerged in France concerning lethal and nonlethal neurological and cardiovascular advents events in cases of accidental and voluntary overdoses with buflomedil, mainly with the $300 \mathrm{mg}$ dosage form (Marimbert 2006).

As a consequence, a number of regulatory actions were taken in France (Marimbert 2006):

1. Change in toxicology information:

- Minimal toxic dose: 3 gram

- Lethal dose: 6 gram.

2. Withdrawal of the $300 \mathrm{mg}$ dosage form, with only $150 \mathrm{mg}$ tablets still available on the market.

3. Deletion of the indication Raynaud phenomenon. Only indication: symptomatic treatment of intermittent claudication.

4. Classification as drug with narrow therapeutic range.

5. Contra-indication in severe renal insufficiency ( $\mathrm{Cr}$ Clearance $<30$ $\mathrm{ml} / \mathrm{min}$ ).

6. Posology: adaptation of the dose in mild to moderate renal insufficiency ( $\mathrm{Cr}$ Clearance 30 to $80 \mathrm{ml} / \mathrm{min}$ ): 1 tablet of $150 \mathrm{mg}$ in the morning and evening, control of renal function before and at regular intervals during treatment, each time recall the adverse neurological and cardiovascular effects in case of no respect or no adaptation of dose in renal insufficiency.

The published trials on buflomedil do not mention numerical safety data, suitable for systematic appraisal. The absence of adverse event data from clinical trials might indicate that the drug is well tolerated within clinical trials, as a number of authors conclude. However, we consulted the international literature and overviews of reported adverse events for regulatory purposes with the following results.

\section{a) The international literature}

The terms which were used to search PUBMED are described in Appendix 2.

Forty- three articles were retrieved, of which 30 were relevant, 10 of which reported on fatal accidents.

From this literature search it is obvious that accidental or voluntary overdose with buflomedil is dangerous. The drug is toxic at doses as low as 3 gram and potentially fatal at moderate doses of 6 gram, with kidney insufficiency as an aggravating factor.

b) Overview of reported adverse events for regulatory purposes (database from May 1979 through to December 2006).

Sixty-five individual reports describing 102 adverse events of interest were identified. Eighty-six percent of all reports came from European countries (in descending order of number of reports: France, Belgium, Germany, Italy, Spain, Greece, Portugal and Switzerland). Nineteen of the 102 events were fatal. Death occurred from cardiac rhythm disturbances and epileptic insults.

Of the 65 patients reported, 24 had taken an overdose (10 of which patients attempting suicide, and the others chronic users on normal dose but not adjusted to renal status), with serious cardiac and neurological complications. Forty-one of the 65 patients were on normal doses and experienced non-specific tachycardia and hypotension expected with vasodilator therapy.

The worldwide reporting rates per 100,000 PTY between 1 December 1994 and 30 November 2006 were 0.27 for suicide, 0.82 for overdose, and 0.48 for fatalities; this reflects a total of 2.9 million patient years.

Our statement on the negative balance between risk and benefit of this drug is based on the one hand on the disappointing results of a systematic review for efficacy data and a number of case reports of toxic effects. None of these elements were sufficient for metaanalytic pooling.

The regulatory agencies of France and Belgium recently took regulatory actions with restrictions in indications and available dosage forms (only $150 \mathrm{mg}$ forms available without extended release formulation). This makes it unpractical to use this drug in daily practice at the doses recommended in clinical trials (600 mg daily). Consequently, it is difficult to prescribe buflomedil, even to patients without renal insufficiency at the doses habitually used in the clinical trials (300 mg twice daily). Most pharmaceutical products on the market were $300 \mathrm{mg}$ tablets. Hence, we conclude that the balance between benefit and risk 
for buflomedil in the symptomatic treatment of intermittent claudication is unfavourable.

\section{AUTHORS' CONCLUSIONS}

\section{Implications for practice}

For buflomedil, evidence of efficacy is scant and the moderately positive results of two included trials are undermined by publication bias.

Positive results from a recent large trial (LIMB) were not confirmed.

Buflomedil has failed to document its efficacy for intermittent claudication, despite extensive utilization and many years of field experience.

Also due to safety concerns, indications become even more restrictive and careful monitoring is advised.
It is time to review the basis of its marketing authorization as it still retains an appeal for patients and for prescribers, despite the lack of evidence of efficacy and emerging safety concerns.

\section{Implications for research}

To refute the hypothesis that buflomedil is not efficacious in intermittent claudication, additional, well executed, high quality, placebo-controlled, double blind trials with sufficient sample sizes need to be performed.

\section{ACKNOWLEDGEMENTS}

We would like to thank Prof MG Bogaert for his work on previous versions of this review. We would like to thank the Cochrane Consumer Network for providing an updated Plain Language Summary. We would also like to thank the Cochrane Peripheral Vascular Diseases Group for their extensive assistance with the most recent update. 


\section{R E F E R E N C E S}

\section{References to studies included in this review}

Diamantopoulos 2001 \{published data only\}

* Diamantopoulos EJ, Grigoriadou M, Ifanti G, Raptis SA. Clinical and hemorheological effects of buflomedil in diabetic subjects with intermittent claudication. International Angiology 2001;20(4):337-44

Diamantopoulos EJ, Raptis SA, Christodoulou-Peters M, Moulopoulos SD. Controlled trial of buflomedil in diabetic peripheral occlusive disease. Ischaemic Diseases and the Microcirculation. New Results. International Symposium. Frankfurt, January 1989:80-4.

\section{Trübestein 1984 \{published data only\}}

Trubestein G, Balzer K, Bisler H, Kluken N, Mahfoud Y, MullerWiefel $\mathrm{H}$, et al. Buflomedil in obstructive arterial disease: Results of a controlled trial [Buflomedil bei arterieller Verschlusskrankheit: Ergebnissse einer kontrollierten Studie]. Deutsche Medizinische Wochenschrift 1982;107(51-52):1957-61.

* Trübestein G, Balzer K, Bisler H, Klüken N, Muller-Wiefel H, Unkel B, et al. Buflomedil in arterial occlusive disease: results of a controlled multicenter study. Angiology 1984;35(8):500-5.

\section{References to studies excluded from this review}

Bisler 1983 \{published data only\}

Bisler H. Clinical response to buflomedil in arterial occlusive disease. Therapiewoche 1983;33:2204-10.

\section{Fonseca 1988 \{published data only\}}

Fonseca V, Mikhaildis DP, Barradas MA, Jeremy JY, Gracey L, Dandona P. Double-blind placebo-controlled trial of buflomedil in intermittent claudication. International Journal of Clinical Pharmacology Research 1988;8(5):377-81.

Levien 1983 \{published data only (unpublished sought but not used)\}

Levien. [Unpublished study] W80-BU-004LJL. S-Africa, 1983. Mentioned in: Walker GA, Mac Hannaford JC. A meta-analysis of randomized, double-blind, placebo-controlled studies of the effect of buflomedil on intermittent claudication. Fundamental and Clinical Pharmacology 1995;9(4):387-94.

\section{Limbs 2008 \{published data only\}}

Leizorovicz A. Buflomedil reduces amputations in patients with peripheral arterial occlusive disease. American College of Cardiology, 54th Annual Scientific Session, Late-Breaking Clinical Trials; 2005 Mar 6-9; Orlando, Florida 2005.

Limbs International Medicinal Buflomedil (LIMB) Study Group, Leizorovicz, A, Becker F. Oral buflomedil in the prevention of cardiovascular events in patients with peripheral arterial obstructive disease: a randomized, placebo-controlled, 4-year study.[see comment]. Circulation 2008;117(6):816-22.
Lowe 1987 \{unpublished data only\}

Lowe GDO, Dandona P, Horrocks M, Cotton LT. [Unpublished study] Evaluation of the clinical efficacy and safety of oral buflomedil hydrochloride in the treatment of intermittent claudication. Study QL/UK.83/2-5. UK, 1987. Mentioned in: Walker GA, Mac Hannaford JC. A meta-analysis of randomized, double-blind, placebo-controlled studies of the effect of buflomedil on intermittent claudication. Fundamental and Clinical Pharmacology 1995;9(4):387-94 (Available from the authors).

Lund 1988 \{published data only (unpublished sought but not used)\} Lund, et al. [Unpublished study] AB-8603. US, 1988. Mentioned in: Walker GA, Mac Hannaford JC. A meta-analysis of randomized, double-blind, placebo-controlled studies of the effect of buflomedil on intermittent claudication. Fundamental and Clinical Pharmacology 1995;9(4):387-94.

Olsson 1986 \{published data only (unpublished sought but not used)\}

Olsson. [Unpublished study] Sweden, 1986. Mentioned in: Walker GA, Mac Hannaford JC. A meta-analysis of randomized, double-blind, placebo-controlled studies of the effect of buflomedil on intermittent claudication. Fundamental and Clinical Pharmacology 1995;9(4):387-94.

Raithel 1985 \{published data only (unpublished sought but not used)\}

Raithel, et al. [Unpublished study] BU-3-P05. Germany, 1985. Mentioned in: Walker GA, Mac Hannaford JC. A meta-analysis of randomized, double-blind, placebo-controlled studies of the effect of buflomedil on intermittent claudication. Fundamental and Clinical Pharmacology 1995;9(4):387-94.

\section{Zinnagl 1986 \{published data only\}}

Zinnagl N. A double blind study of the effects of buflomedil in 40 patients with arterial occlusive disease in Stage IIB [Doppelblindstudie über die Wirksamkeit von Buflomedil an 40 Patienten mit arterieller Verschlusskrankheit im Stadium IIB]. International Symposium on Conservative Therapy of Arterial Occlusive Disease. Bonn, May 23-25. New York: Georg Thieme Verlag, 1986.

\section{Additional references}

\section{Baitsch 1983}

Baitsch R. [Unpublished study]. BU-2-DO2. Germany, 1983. Mentioned in: Walker GA, Mac Hannaford JC. A meta-analysis of randomized, double-blind, placebo-controlled studies of the effect of buflomedil on intermittent claudication. Fundamental and Clinical Pharmacology 1995; Vol. 9, issue 4:387-94.

\section{Bevan 1992}

Bevan EG, Waller PC, Ramsay LE. Pharmacological approaches to the treatment of intermittent claudication. Drugs and Aging 1992;2(2):125-36. 


\section{Cameron 1988}

Cameron HA, Waller PC, Ramsay LE. Drug treatment of intermittent claudication: critical analysis of the methods and findings of published clinical trials, 1965-1985. British Journal of Clinical Pharmacology 1988;26(5):569-76.

\section{Diamantopoulos 1989}

Diamantopoulos EJ, Raptis SA, Christodoulou-Peters M, Moulopoulos SD. Controlled trial of buflomedil in diabetic peripheral occlusive disease. Ischaemic diseases and the microcirculation. New results. International Symposium. Frankfurt, January 1989:80-4.

\section{Dickersin 1994}

Dickersin K, Scherer R, Lefebvre C. Identifying relevant studies for systematic reviews. BMJ 1994;309(6964):1286-91.

\section{Fontaine 1954}

Fontaine VR, Kim M, Kieny R. Surgical treatment for peripheral vascular disease [Die chirurgische Behandlung der peripheren Durchblutungsstorungen]. Helvetica Chirurgica Acta 1954;5/6:499-533.

\section{Gardner 1989a}

Gardner MJ, Altman DG. Estimating with confidence. In: Gardner MJ, Altman DG editor(s). Statistics with confidence: confidence intervals and statistical guidelines. London: BMJ Publishing Group, 1989:3-5.

\section{Gardner 1989b}

Gardner MJ, Altman DG. Estimation rather than hypothesis testing: confidence intervals rather than P values. In: Gardner MJ, Altman DG editor(s). Statistics with confidence: confidence intervals and statistical guidelines. London: BMJ Publishing Group, 1989:6-19.

\section{Gardner 1989c}

Altman DG, Gardner MJ. Calculating confidence intervals for means and their differences. In: Gardner MJ, Altman DG editor(s). Statistics with confidence: confidence intervals and statistical guidelines. London: BMJ Publishing Group, 1989:20-7.

\section{Gardner 1989d}

Gardner MJ, Altman DG. Tables for calculation of confidence intervals. In: Gardner MJ, Altman DG editor(s). Statistics with confidence: confidence intervals and statistical guidelines. London: BMJ Publishing Group, 1989:111-29.

\section{Jadad 1996}

Jadad RJ, Moore RA, Carroll D, Jenkinson C, Reynolds DJ, Gavaghan DJ, et al. Assessing the quality of reports of randomized clinical trials: is blinding necessary?. Controlled Clinical Trials 1996;17:1-12.

\section{Jepson 1997}

Jepson RG, Kleijnen J, Leng GC. Garlic for peripheral arterial occlusive disease. Cochrane Database of Systematic Reviews 2006, Issue 2. [DOI: 10.1002/14651858.CD000095]

\section{Kleijnen 1998}

Kleijnen J, Mackerras D. Vitamin E for intermittent claudication. Cochrane Database of Systematic Reviews 1998, Issue 1. [DOI: 10.1002/14651858.CD000987]

\section{Leng 2000}

Leng GC, Fowler B, Ernst E. Exercise for intermittent claudication. Cochrane Database of Systematic Reviews 2000, Issue 2. [DOI: 10.1002/14651858.CD000990]

\section{Liard 1997}

Liard F, Benichou AC, Gamand S, Lehert P. The effects of naftidrofuryl on quality of life. Disease Management Health Outcomes 1997;2(Suppl 1):71-8.

\section{Marimbert 2006}

Marimbert J. Lettre aux professionnels de santé:

Pharmacovigilance et la sécurité d'emploi du buflomédil [Letter to health professionals: Pharmacovigilance and safety of use of buflomedil]. Agence française de sécurité sanitaire des produits de santé. 13 November 2006.

\section{Mulrow 1999}

Mulrow CD, Oxman AD. Cochrane Collaboration Handbook (In: The Cochrane Library, Issue 3). Oxford: Update Software, 1999.

\section{Price 2001}

Price JF, Leng GC. Steroid sex hormones for lower limb atherosclerosis. Cochrane Database of Systematic Reviews 2005, Issue 3. [DOI: 10.1002/14651858.CD000188]

\section{Schulz 1995}

Schulz KF, Chalmers IC, Hayes RJ, Altman DG. Empirical evidence of bias. Dimensions of methodological quality associated with estimates of treatment effects in controlled trials. Journal of the American Medical Association 1995;273(5):408-12.

\section{Spengel 1997}

Spengel A, Brown TM, Dietze S, Kirchberger I, Comte S. The claudication scale (CLAU-S). New disease-specific quality-of-life instrument in intermittent claudication. Disease Management Health Outcomes 1997;2(Suppl 1):65-70.

\section{Verhaeghe 1998}

Verhaeghe R. Epidemiology and prognosis of peripheral obliterative arteriopathy. Drugs 1998;56(suppl 3):1-10.

\section{Walker 1995}

Walker GA, Mac Hannaford JC. A meta-analysis of randomized, double-blind, placebo-controlled studies of the effect of buflomedil on intermittent claudication. Fundamental and Clinical Pharmacology 1995;9(4):387-94.

\section{Wood 2005}

Wood S. Buflomedil to reduce clinical complications of peripheral artery disease? Maybe, maybe not. www.theheart.org/article/402581.do 11 March 2005, issue accessed 26 April 2007. 


\section{Wurzinger 1987}

Wurzinger LJ, Schmid-Schonbein H. Effect of buflomedil on epinephrine-enhanced platelet aggregation in vitro and ex vivo. Arzneimittel-Forschung 1987;37(10):1113-5.

\section{References to other published versions of this review \\ De Backer 2000}

De Backer TLM, Vander Stichele RH, Bogaert MG. Buflomedil for intermittent claudication. Cochrane Database of Systematic Reviews 2000, Issue 2. [DOI: 10.1002/14651858.CD000988]

\section{De Backer 2007}

De Backer TLM, Bogaert MG, Vander Stichele RH. Buflomedil for intermittent claudication. Cochrane Database of Systematic Reviews 2007, Issue 4. [DOI: 10.1002/14651858.CD000988.pub2]

\section{de Backer 2008}

de Backer TLM, Bogaert M, Vander Stichele R. Buflomedil for intermittent claudication. Cochrane Database of Systematic Reviews 2008, Issue 1. [DOI: 10.1002/14651858.CD000988.pub3]

* Indicates the major publication for the study

\section{CHARACTERISTICS OF STUDIES}

Characteristics of included studies [ordered by study ID]

Diamantopoulos 2001

Study design: States randomized, double-blinded.
Method of randomization: Not stated.
Blinding: Double-blinded.
Dropouts: 2 patients from the buflomedil group, because they felt better, and 4 from the placebo
group; 1 for no apparent reason, 1 fatal AMI, 1 underwent surgery and 1 failed to report.

Participants

Country: Greece.

Setting: Clinic.

No. 40 patients; (21 buflomedil, 19 placebo).

Gender: 36 males (19 buflomedil, 17 placebo), 4 females ( 2 buflomedil, 2 placebo).

Age: mean 60.1 years (range 39 to 77 ).

Inclusion criteria: All had maturity onset diabetes mellitus (11 insulin-dependent, 29 non-insulin dependent, mean duration 14 years) mean duration PAOD 3.4 years, walking distance < $400 \mathrm{~m}$ SBP indices at both ankles estimated by Doppler.

At the start of a 4-week observation period before entry into the study, patients were given a full physical examination and an ECG at rest and after exercise on a treadmill $\left(3.6 \mathrm{~km} / \mathrm{h}\right.$ at $\left.12.5^{\circ} \mathrm{C}\right)$.

Exclusion criteria: Vascular surgery or specific physical training, participation in another study, history of cerebrovascular accident or coronary heart disease, concomitant therapy that could influence any of the parameters to be studied, evidence of excessive Monckeberg's sclerosis, diabetic retinopathy, severe renal, hepatic or cardiopulmonary impairment, uncontrolled arterial hypertension, previous AMI, angina pectoris, severe cardiac arrhythmias, evidence of peripheral sensory neuropathy, arterial bleeding, pregnancy or lactation, allergy to any medication, history of convulsions or other central nervous system diseases, grossly over- or under-weight diabetics based on tables size-weight, musculoskeletal disorders limiting walking ability.

Control: Matching placebo tablets.

Compliance checked every 3 to 4 weeks by patients returning their bottles to the outpatient clinic where remaining tablets were counted.

Duration: Six months. 
Diamantopoulos 2001 (Continued)

Outcomes

Primary: Distances at 6 months constituted the primary response variables. PFWD and MWD measured at entry (baseline) and after 3 and 6 months' treatment using a standardized exercise test on the tread$\operatorname{mill}\left(3.6 \mathrm{~km} / \mathrm{h}\right.$ at $\left.12.5^{\circ} \mathrm{C}\right)$.

Secondary: Not stated.

\section{Notes}

\section{Risk of bias}

Bias Authors' judgement Support for judgement

Allocation concealment Unclear risk
(selection bias)

(selection bias)

Trübestein 1984

Study design: States randomized, double-blinded.
Method of randomization: Not stated.
Blinding: Double-blinded.
Dropouts: 8 in the placebo group and 12 in the buflomedil group, leaving 93 for analysis (46 in placebo
group, 47 in buflomedil group).

Participants
Setting: Clinic.
No.: 113 patients.
Age: 50 to 70 years old.
Gender: Not stated.
Inclusion criteria: Symptoms of intermittent claudication for 6 months to 5 years and PFWD of 50 to 400
m.
After a four-week run-in period during which all patients received placebo and other vasoactive drugs
were stopped, patients were checked to test whether their PFWD differed by not more than $30 \%$ from
the value at the beginning of the run-in period (mean of two consecutive measurements). Patients
were then allocated randomly to treatment groups.
Exclusion criteria: Special physical training for at least six months prior to study start; systolic blood
pressure at the ankle of less than 70 mm Hg, diabetic microangiopathy or necrosis, inflammatory vas-
cular disease such as endarteritis obliterans, coronary heart disease with angina pectoris, myocardial
insufficiency, respiratory insufficiency, arthropathy, symptoms of severe liver or kidney disease, labo-
ratory values of more than $10 \%$ outside normal range, pregnancy, beta-blockers and any other vasoac-
tive drugs.

Interventions
All patients received placebo tablets (four daily - 2 in the morning, one at midday and one in the evening) for four weeks run-in.
Treatment: Buflomedil $600 \mathrm{mg}$ daily $(2 \times 150 \mathrm{mg}$ in the morning, $1 \times 150 \mathrm{mg}$ at midday and $1 \times 150 \mathrm{mg}$ in the evening.)
Control: Matching placebo.
Duration: 12 weeks treatment.


Trübestein 1984 (Continued)

(16 weeks in total including the 4 week run-in period.)

Outcomes Primary: PFWD and MWD were measured by treadmill ( $5 \mathrm{~km} / \mathrm{h}$ at $10^{\circ}$ elevation).

Ankle-arm pressures were measured by Doppler at rest and after exercise and pressure differences (brachial artery-posterior tibial artery) were calculated.

Measurements were performed at days 28, 56, and 84 .

\section{Notes}

\section{Risk of bias}

\begin{tabular}{lll}
\hline Bias & Authors' judgement & Support for judgement \\
\hline $\begin{array}{l}\text { Allocation concealment } \\
\text { (selection bias) }\end{array}$ & Unclear risk & B - Unclear \\
\hline
\end{tabular}

AMI: acute myocardial infarction

ECG: electrocardiogram

MWD: maximal walking distance

PAOD: peripheral arterial occlusive disease

PFWD: pain-free walking distance

SBP: systolic blood pressure

\section{Characteristics of excluded studies [ordered by study ID]}

\begin{tabular}{ll}
\hline Study & Reason for exclusion \\
\hline Bisler 1983 & $\begin{array}{l}\text { A small study }(\mathrm{N}=38) \text { with a mixed protocol of } 14 \text { days intravenous therapy }(2 \times 100 \mathrm{mg}) \text { followed } \\
\text { by eight weeks oral therapy (daily dose of } 600 \mathrm{mg} \text { in three doses. The duration of the study was too } \\
\text { short ( } 8 \text { weeks) for inclusion. At randomization there were } 20 \text { participants in the active group ver- } \\
\text { sus } 18 \text { in the placebo group. Percentages of smokers and diabetics were not given. No mention of: } \\
\text { dropouts, total number of patients screened, or how many of the original } 38 \text { patients completed } \\
\text { the study. }\end{array}$ \\
\hline
\end{tabular}

A small study ( $\mathrm{N}=34)$ with six poorly described dropouts (two in the active group, four in the placebo group). $23 \%$ of participants were diabetic. Daily dosage of $600 \mathrm{mg}$ given in two doses. The primary aim of the study was to investigate whether buflomedil inhibits platelet aggregation in patients with PAOD. The secondary endpoints were PFWD, MWD and subjective improvement. The results of the primary endpoint were negative and so the researchers shifted attention to the secondary outcomes. Results of treadmill tests expressed in time units and not in distance units. Standard deviations of results not given.

\section{Levien 1983}

Study 08 in the meta-analysis of Walker and Mac Hannaford, but not published. Twenty-six participants with a mean age of 63 years, treated for six months with $600 \mathrm{mg}$ of buflomedil or placebo. An effect size of -0.5 to 1.2 mentioned. We could not obtain this study. Example of publication bias.

\section{Limbs 2008}

Although this is a large, double-blind RCT, we excluded this study because PFWD and MWD were not measured by an objective standardized test. See Table 1 for details of the trial.

Lowe 1987

Unpublished multicenter study mentioned in the meta-analysis of Walker and Mac Hannaford. We obtained this trial as confidential material with the help of the Cochrane PVD Group. The trial was rather short (12 weeks), daily dosage of $600 \mathrm{mg}$ given in three doses, and results did not provide statistics on variation (SD or SEM). At randomization there were 97 participants in the active group versus 104 in the placebo group. Dropouts (29 in active group and 25 in placebo group) and proto- 


\begin{tabular}{|c|c|}
\hline Study & Reason for exclusion \\
\hline & $\begin{array}{l}\text { col violations were mentioned but not well described. This study clearly showed negative results } \\
\text { for the PFWD. }\end{array}$ \\
\hline Lund 1988 & $\begin{array}{l}\text { Study } 11 \text { in the meta-analysis of Walker and Mac Hannaford, but not published. One hundred and } \\
\text { sixty-eight participants were treated for three months with } 600 \mathrm{mg} \text { of buflomedil or placebo. We } \\
\text { could not retrieve this study. Example of publication bias. }\end{array}$ \\
\hline Olsson 1986 & $\begin{array}{l}\text { Study } 10 \text { in the meta-analysis of Walker and Mac Hannaford, but not published. Sixty patients } \\
\text { (mean age?) participated in this study and were treated for three months. An effect size of - } 0.3 \text { to } 07 \\
\text { was given. We could not retrieve this study. Example of publication bias. }\end{array}$ \\
\hline Raithel 1985 & $\begin{array}{l}\text { Study } 09 \text { in the meta-analysis of Walker and Mac Hannaford, but not published. One hundred and } \\
\text { five participants were treated for four months with a daily dose of } 600 \mathrm{mg} \text { buflomedil or placebo. } \\
\text { An effect size of }-0.2 \text { to } 0.6 \text { was given. We could not obtain this study. Example of publication bias. }\end{array}$ \\
\hline Zinnagl 1986 & $\begin{array}{l}\text { A small study }(\mathrm{N}=40) \text {, with a short double blind phase of } 60 \text { days, inadequate reporting of trial pro- } \\
\text { cedures, and no data on variability of results. Total daily dosage was } 600 \mathrm{mg} \text { given in four doses. } \\
\text { Percentages of smokers and diabetics were not given. At randomization there were } 20 \text { participants } \\
\text { in each group and there were no dropouts. }\end{array}$ \\
\hline
\end{tabular}

\section{DATA AND ANALYSES}

\section{Comparison 1. Buflomedil versus placebo}

\begin{tabular}{llllll}
\hline Outcome or subgroup title & $\begin{array}{l}\text { No. of } \\
\text { studies }\end{array}$ & $\begin{array}{l}\text { No. of } \\
\text { partici- } \\
\text { pants }\end{array}$ & Statistical method & Effect size \\
\hline $\begin{array}{l}\text { 1 Painfree walking distance. Meters } \\
\text { gain }\end{array}$ & 2 & 127 & Mean Difference (IV, Random, 95\% CI) & $76.92[32.32,121.52]$ \\
\hline $\begin{array}{l}\text { 2 Maximal walking distance. Meters } \\
\text { gain }\end{array}$ & 2 & 127 & Mean Difference (IV, Random, 95\% CI) & $112.64[27.73,197.54]$ \\
\hline
\end{tabular}

Analysis 1.1. Comparison 1 Buflomedil versus placebo, Outcome 1 Painfree walking distance. Meters gain.

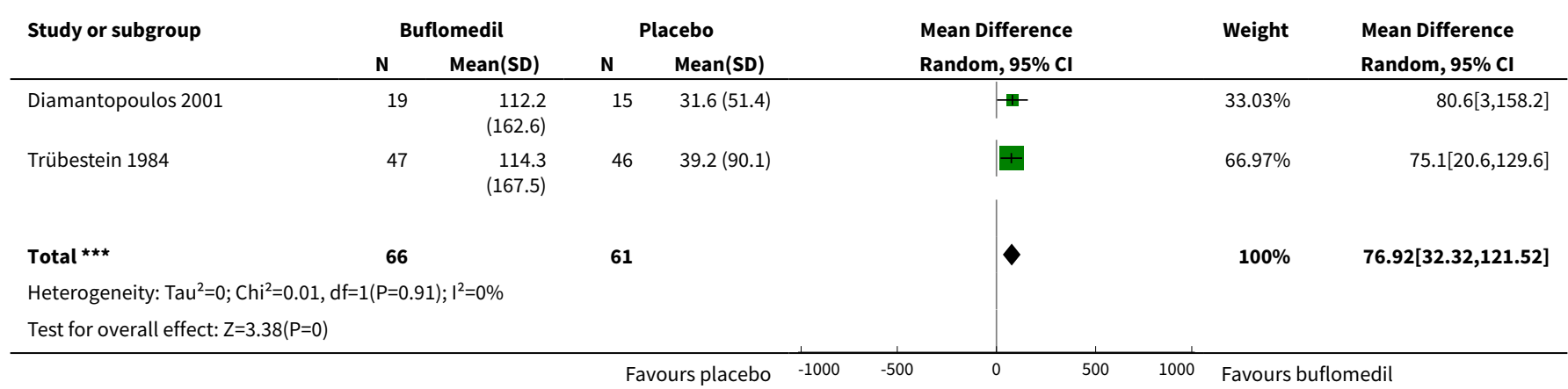


Analysis 1.2. Comparison 1 Buflomedil versus placebo, Outcome 2 Maximal walking distance. Meters gain.

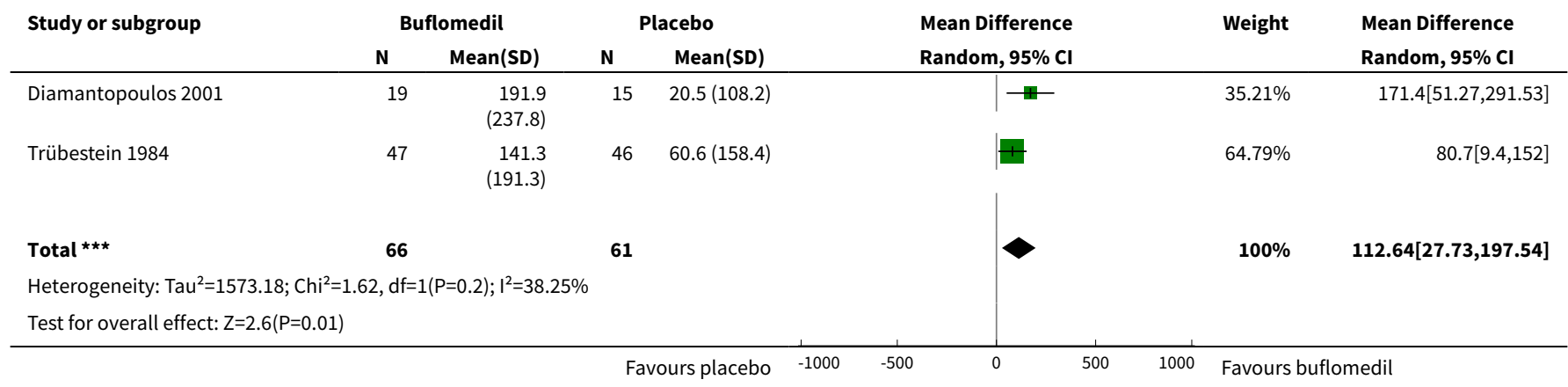

\section{ADDITIONAL TABLES}

Table 1. Limbs 2008 trial

Methods Study design: international, multicenter, randomized, placebo-controlled, double-blinded.
Participating centers: Czech Republic, France, Hungary, Russia
Method of randomization:a centralized computer-generated schedule (1:1 randomization in blocks
of 6 and stratified by center and creatinine clearance)
Blinding:double-blind; buflomedil and placebo were indistinguishable in terms of shape, smell and
appearance

Statistical analysis: primary efficacy outcome performed on the intention-to-treat population; safety analysis performed on the as-treated population;

Dropouts:buflomedil: 223 patients permanently stopped treatment prior to study completion (including death) and 5 patients lost to follow-up; placebo: 219 patients permanently stopped treatment prior to study completion (including death) and 10 patients lost to follow-up

\section{Participants}

Patients $>40$ y with documented peripheral arterial obstructive disease, intermittent claudication, and an ankle-brachial index between 0,30 and 0,80

Patients were excluded from the study if they presented the following characteristics: ischemic rest pain (i.e., Fontaine's stage III PAD), ulceration or gangrene (i.e., Fontaine's stage IV PAD), iliac or common femoral artery stenosis or occlusion, arterial occlusion of embolic origin, Buerger disease, or any nonatherosclerotic arterial

disease of the lower limbs. Likewise, patients with confounding factor(s) interfering with the evaluation of PAD (e.g., major stroke sequel or major amputation of a lower limb) or the effect of the study treatment (e.g., patients in whom vasoactive treatments could not be discontinued or who were already under treatment with buflomedil

started 1 month previously) were not recruited. Other exclusion criteria were acute myocardial infarction or stroke within the last 45 days, vascular or endovascular surgery within the last 45 days or planned within the next month, active cancer, poor short-term vital prognosis, and thrombophilia. Finally, pregnant or breast-feeding women and women of childbearing age not using effective contraception could not participate in the study.

$\mathrm{n}=2078$ patients randomized: 1043 to buflomedil, 1035 to placebo

\begin{tabular}{ll}
\hline Interventions & Long-term administration (mean 33 months) of oral buflomedil or placebo \\
\hline Outcomes & $\begin{array}{l}\text { 1. The primary efficacy outcome was critical cardiovascular events, defined as the composite of } \\
\text { cardiovascular death (including sudden death of presumed cardiac origin), nonfatal myocardial in- }\end{array}$
\end{tabular}


Table 1. Limbs 2008 trial

farction, nonfatal stroke, symptomatic deterioration of peripheral arterial obstructive disease, or leg amputation

2. Secondary efficacy end points included the individual components of the primary efficacy outcome, death resulting from any cause, and all cardiovascular events. Other secondary efficacy endpoints were pain-free and maximal walking distances (as assessed by patient questioning), ABI values, and quality of life (i.e. ability to perform daily life activities according to the patient using a 0to $100-\mathrm{mm}$ subjective visual analogue scale)

3. The primary safety outcome was adverse events, with special attention paid to myoclonia and convulsion

Although this is a large, double-blind RCT, we excluded this study because PFWD and MWD were not measured by an objective standardized test.

Because of safety reasons, oral buflomedil $300 \mathrm{mg}$ tablets are not anymore on the market

From certain experts in the vascular field (Olin J, NY, USA) criticism has been made on the reliability of the study data

An associated editorial by MS Conte (Boston, MA, USA) (Circulation 2008;117:717-9) softened the conclusion of the LIMB study group authors that the use of buflomedil should be considered in addition to an antiplatelet agent in patients with peripheral arterial obstructive disease and intermittent claudication

There was also a letter to the Editor (Letter by De Backer et al regarding article, "Oral buflomedil in the prevention of cardiovascular events in patients with peripheral arterial obstructive disease: a randomized, placebo-controlled, 4-year study". Circulation 2008;118;e151)

\section{APPENDICES}

\section{Appendix 1. CENTRAL search strategy}

\begin{tabular}{llc}
\hline$\# 1$ & MeSH descriptor: [Arteriosclerosis] this term only & 893 \\
\hline$\# 2$ & MeSH descriptor: [Arteriolosclerosis] this term only & 0 \\
\hline$\# 3$ & MeSH descriptor: [Arteriosclerosis Obliterans] this term only & 71 \\
\hline$\# 4$ & MeSH descriptor: [Atherosclerosis] this term only & 382 \\
\hline$\# 5$ & MeSH descriptor: [Arterial Occlusive Diseases] this term only & 755 \\
\hline$\# 6$ & MeSH descriptor: [Intermittent Claudication] this term only & 711 \\
\hline$\# 7$ & MeSH descriptor: [Ischemia] this term only & 753 \\
\hline$\# 8$ & MeSH descriptor: [Peripheral Vascular Diseases] explode all trees & 2150 \\
\hline$\# 9$ & MeSH descriptor: [Vascular Diseases] this term only & 381 \\
\hline$\# 10$ & MeSH descriptor: [Leg] explode all trees and with qualifiers: [Blood supply - BS] & 1073 \\
\hline$\# 11$ & MeSH descriptor: [Femoral Artery] explode all trees & 720
\end{tabular}




\begin{tabular}{|c|c|c|}
\hline \#12 & MeSH descriptor: [Popliteal Artery] explode all trees & 250 \\
\hline \#13 & MeSH descriptor: [lliac Artery] explode all trees & 151 \\
\hline \#14 & MeSH descriptor: [Tibial Arteries] explode all trees & 29 \\
\hline \#15 & (atherosclero* or arteriosclero* or PVD or PAOD or PAD) & 17142 \\
\hline \#16 & $\left(\right.$ arter $\left.^{\star}\right)$ near $\left({ }^{\star}\right.$ occlus $^{\star}$ or steno* $^{\star}$ or obstuct ${ }^{\star}$ or lesio* or block ${ }^{\star}$ or obliter $\left.{ }^{\star}\right)$ & 4863 \\
\hline \#17 & (vascular) near (*occlus* or steno* or obstuct* or lesio* or block* or obliter*) & 1376 \\
\hline \#18 & $\left(\right.$ vein $\left.^{\star}\right)$ near $\left({ }^{\star}\right.$ occlus $^{\star}$ or steno* or obstuct ${ }^{\star}$ or lesio* or block ${ }^{\star}$ or obliter $\left.{ }^{\star}\right)$ & 710 \\
\hline \#19 & $\left(\right.$ veno $\left.^{\star}\right)$ near $\left({ }^{\star}\right.$ occlus $^{\star}$ or steno* or obstuct ${ }^{\star}$ or lesio* or block ${ }^{\star}$ or obliter $)$ & 976 \\
\hline \#20 & $\left(\right.$ peripher $\left.^{\star}\right)$ near $\left({ }^{\star}\right.$ occlus $^{\star}$ or steno ${ }^{\star}$ or obstuct ${ }^{\star}$ or lesio* or block ${ }^{\star}$ or obliter ) & 1356 \\
\hline \#21 & peripheral near/3 dis* & 3224 \\
\hline \#22 & arteriopathic & 9 \\
\hline \#23 & (claudic ${ }^{\star}$ or hinken*) & 1434 \\
\hline \#24 & (isch* or CLI) & 16728 \\
\hline \#25 & dysvascular* & 13 \\
\hline \#26 & leg near/4 (obstruct* or occlus* or steno* or block* or obliter*) & 175 \\
\hline \#27 & limb near/4 (obstruct* or occlus* or steno* or block* or obliter ${ }^{\star}$ ) & 227 \\
\hline \#28 & $\left(\right.$ lower near $/ 3$ extrem ${ }^{\star}$ ) near/4 (obstruct ${ }^{\star}$ or occlus ${ }^{\star}$ or steno* or block ${ }^{\star}$ or obliter ${ }^{\star}$ ) & 136 \\
\hline \#29 & $\begin{array}{l}\text { (aort* or iliac or femoral or popliteal or femoro* or fempop* or crural) near/3 (obstruct }{ }^{\star} \text { or } \\
\text { occlus }^{\star} \text { ) }\end{array}$ & 324 \\
\hline \#30 & $\begin{array}{l}\# 1 \text { or } \# 2 \text { or } \# 3 \text { or } \# 4 \text { or } \# 5 \text { or } \# 6 \text { or } \# 7 \text { or } \# 8 \text { or } \# 9 \text { or } \# 10 \text { or } \# 11 \text { or } \# 12 \text { or } \# 13 \text { or } \# 14 \text { or } \# 15 \text { or } \\
\# 16 \text { or } \# 17 \text { or } \# 18 \text { or } \# 19 \text { or } \# 20 \text { or } \# 21 \text { or } \# 22 \text { or } \# 23 \text { or } \# 24 \text { or } \# 25 \text { or } \# 26 \text { or } \# 27 \text { or } \# 28 \text { or } \\
\# 29\end{array}$ & 39487 \\
\hline \#31 & buflomedil:ti,ab,kw (Word variations have been searched) & 142 \\
\hline \#32 & bufedil or buflan:ti,ab,kw (Word variations have been searched) & 0 \\
\hline \#33 & diarfin or fonzylane:ti,ab,kw (Word variations have been searched) & 3 \\
\hline \#34 & irrodan:ti,ab,kw (Word variations have been searched) & 0 \\
\hline \#35 & lofton or loftyl:ti,ab,kw (Word variations have been searched) & 3 \\
\hline \#36 & $\# 31$ or \#32 or \#33 or \#34 or \#35 & 145 \\
\hline \#37 & $\# 30$ and \#36 in Trials & 83 \\
\hline
\end{tabular}




\section{Appendix 2. Authors' 2007 Pubmed search terms for safety data}

(("Pyrrolidines/adverse effects"[Mesh] OR "Pyrrolidines/toxicity"[Mesh]) OR "Pyrrolidines/poisoning"[Mesh])) AND ("buflomedil"[Substance Name] OR Buflomedil[Text Word])

\section{WHAT'S NEW}

\begin{tabular}{lll}
\hline Date & Event & Description \\
\hline 12 February 2013 & New search has been performed & $\begin{array}{l}\text { Searches were rerun but no new studies were identified for inclu- } \\
\text { sion or exclusion. }\end{array}$ \\
\hline 12 February 2013 & $\begin{array}{l}\text { New citation required but conclusions } \\
\text { have not changed }\end{array}$ & $\begin{array}{l}\text { Searches were rerun but no new studies were identified for inclu- } \\
\text { sion or exclusion. Minor copy edits made to the text. One author } \\
\text { stepped down from author team. }\end{array}$ \\
\hline
\end{tabular}

\section{H I S T O R Y}

Protocol first published: Issue 1, 1998

Review first published: Issue 1, 2001

\begin{tabular}{lll}
\hline Date & Event & Description \\
\hline 28 April 2009 & New search has been performed & $\begin{array}{l}\text { LIMB trial added to excluded studies. Copy edits made to the } \\
\text { text. }\end{array}$ \\
\hline 9 May 2008 & Amended & Converted to new review format. \\
\hline 11 November 2007 & $\begin{array}{l}\text { New citation required and conclusions } \\
\text { have changed }\end{array}$ & $\begin{array}{l}\text { Substantive amendment. Additional safety and efficacy data } \\
\text { added in the light of withdrawal of 300 mg tablets in France. } \\
\text { Safety considerations expanded. }\end{array}$ \\
\hline 20 August 2007 & $\begin{array}{l}\text { New citation required but conclusions } \\
\text { have not changed }\end{array}$ & \begin{tabular}{l} 
Citation order changed. \\
\hline
\end{tabular}
\end{tabular}

\section{CONTRIBUTIONS OF AUTHORS}

Dr TL De Backer: Evaluated retrieved trials and was primary author of the manuscript.

Dr RH Vander Stichele: Assisted in designing of the review, searching the literature, evaluating retrieved trials and the manuscript editing.

\section{DECLARATIONS OF INTEREST}

None known

\section{SOURCES OF SUPPORT}

\section{Internal sources}

- Heymans Institute of Pharmacology, Medical School, University of Gent, Belgium.

\section{External sources}

- Chief Scientist Office, Scottish Government Health Directorates, The Scottish Government, UK. The PVD Group editorial base is supported by the Chief Scientist Office. 


\section{N D EX TERMS}

\section{Medical Subject Headings (MeSH)}

Administration, Oral; Double-Blind Method; Intermittent Claudication [ ${ }^{\star}$ drug therapy]; Publication Bias; Pyrrolidines [ ${ }^{\star}$ therapeutic use]; Randomized Controlled Trials as Topic; Treatment Outcome; Vasodilator Agents [ ${ }^{\star}$ therapeutic use]

\section{MeSH check words}

Humans 